\title{
Progressive pseudorheumatoid dysplasia: report of a family and review
}

\author{
Hatem E El-Shanti, Hamzi Z Omari, Hani I Qubain
}

\section{Department of}

Paediatrics, School of

Medicine, Jordan

University of Science

and Technology, Irbid,

Jordan

H E El-Shanti

Department of

Radiology, School of

Medicine, Jordan

University of Science

and Technology, Irbid,

Jordan

H Z Omari

\section{Department of}

Medicine, University

of Jordan, Amman,

Jordan

H I Qubain

Correspondence to:

Dr El-Shanti, PO Box 3211

Irbid, 211-10 Jordan.

Received 8 October 1996

Revised version accepted for publication 23 January 1997
Paediatrics, School of

\begin{abstract}
Progressive pseudorheumatoid dysplasia is an inherited skeletal dysplasia with radiographic changes notably in the spine, similar to spondyloepiphyseal dysplasia tarda. There is also articular cartilage involvement which gives it some clinical resemblance to rheumatoid arthritis. We report here on six subjects from one inbred family from Jordan. Based on previously published reports and this one, we review the clinical and radiological features and discuss the genetics and differential diagnosis of the disorder. We suggest the addition of the word "spondyloepiphyseal" to the name adopted by the International Working Group on Constitutional Diseases of Bone, to become "progressive pseudorheumatoid spondyloepiphyseal dysplasia". We also speculate on candidate genes for this disorder. (F Med Genet 1997;34:559-563)
\end{abstract}

Keywords: dysplasia; pseudorheumatoid; genu varum; platyspondyly

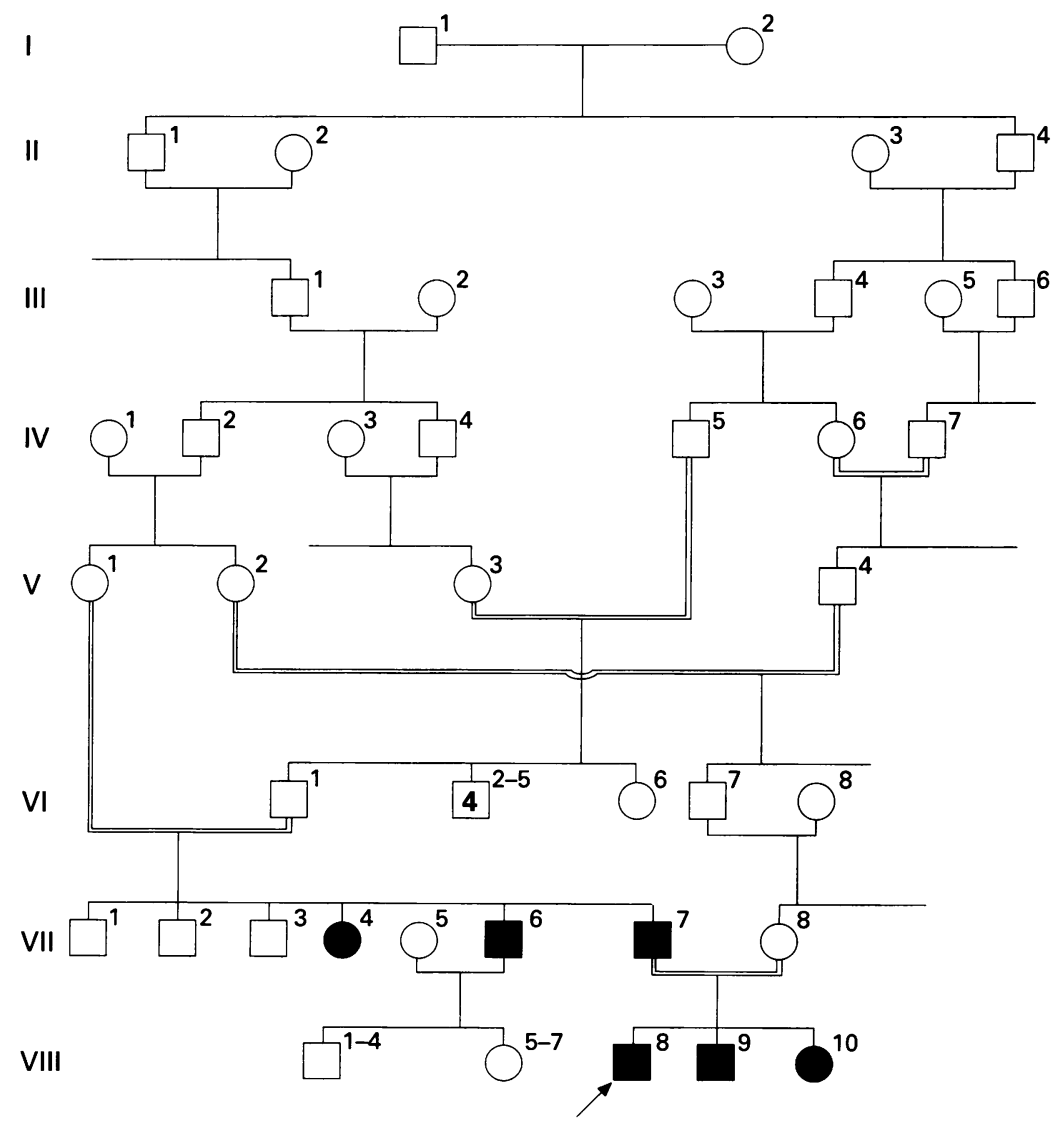

Figure 1 The pedigree of the family. There are several consanguineous marriages. Black symbols denote affected subjects.
Progressive pseudorheumatoid dysplasia (spondyloepiphyseal dysplasia tarda with progressive arthropathy (SEDT-PA) or progressive pseudorheumatoid arthropathy of childhood (PPAC), MIM 208.230) is an inherited skeletal dysplasia with radiographic changes in the spine similar to spondyloepiphyseal dysplasia tarda and clinical, though not radiographic, resemblance to rheumatoid arthritis. ${ }^{1}$ It is a progressive chondropathy affecting primarily the articular cartilage with characteristic skeletal abnormalities notably in the spine. $^{2}$ Although a few early reports may have dealt with the same disorder, ${ }^{34}$ the clinical and radiographic picture are outlined in two main reports. ${ }^{12}$ Several reports have followed, increasing the number of patients and confirming the autosomal recessive mode of inheritance. $^{5-16}$ The International Working Group on Constitutional Diseases of Bone had adopted the term "progressive pseudorheumatoid dysplasia" to avoid confusion with other disease entities. ${ }^{17} \mathrm{We}$ present here six affected subjects from one highly inbred family distributed over two successive generations (fig 1). We also review the published reports pertaining to the clinical, radiographic, and genetic aspects of this condition.

\section{Case reports}

CASE 1

The proband, VIII.8, currently a 7 year old male, presented to physicians three years ago with progressive bowing of the lower limbs, genu varum (fig 2 ). He walked at the age of 1 year and the bowing became noticeable by the age of 2 years. His height on several occasions was on the 10th centile for age, without correction for the genu varum. The remainder of his growth parameters, as well as his intelligence, were normal. At the age of 6 years he started to show minimal fusiform swellings of the metacarpophalangeal and interphalangeal joints with slight limitation of extension of the fingers. Joint pain was not a constant complaint but became evident when tired. He underwent corrective surgery for the genu varum at the age of 6 years.

The radiological findings at the age of 2 years were minimal irregularity of the medial aspect of the epiphyses and the metaphyses of the distal femora and proximal tibiae and mild genu varum deformity. At the age of 6 years, the radiographs of the spine showed platyspondyly, in particular at the thoracolumbar junction, with obvious irregularity of the vertebral end plates. Lower limb radiographs showed marked genu varum deformity with medial beaking of the upper tibial shafts and metaphyseal 


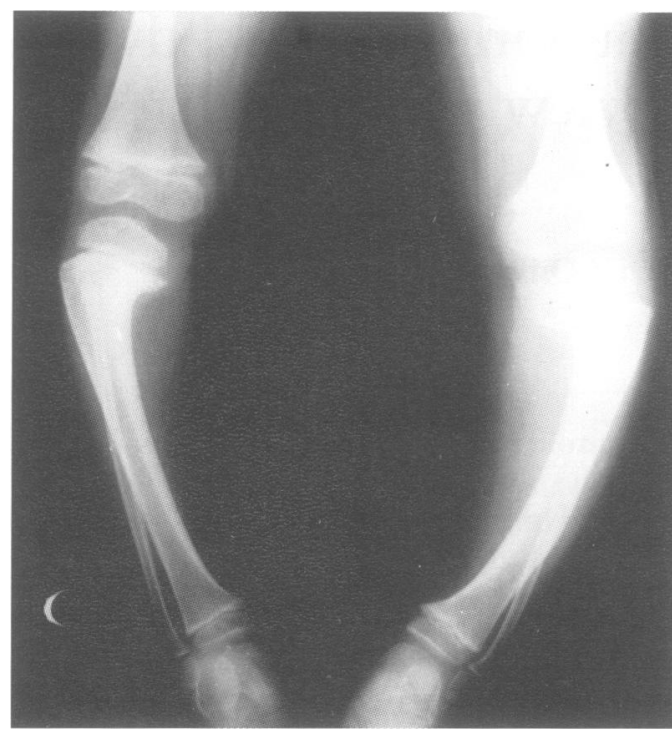

Figure 2 Subject VIII. 8 (proband) at the age of 4 years: anteroposterior view of the knee showing flattened and irregular condylar surfaces. There is marked genu varum with medial beaking of the upper tibial shaft.

irregularity of the proximal and distal tibiae. There was mild enlargement and flattening of the epiphyses of the distal femora. Radiographs of the hands showed mild enlargement of the metacarpal and phalangeal epiphyses.

CASE 2

The brother of the proband, VIII.9, currently $51 / 2$ years old, walked at the age of 1 year and showed bowing around the age of $21 / 2$ years. His height was on the 50th centile for age. The radiological findings were similar to the early findings in the proband.

CASE 3

The sister of the proband, VIII.10, currently 4 years old, walked at the age of 1 year and showed bowing around the age of $2^{1 / 2}$ years. Her height was on the 90th centile for her age. The radiological findings were similar to the early findings in the proband.

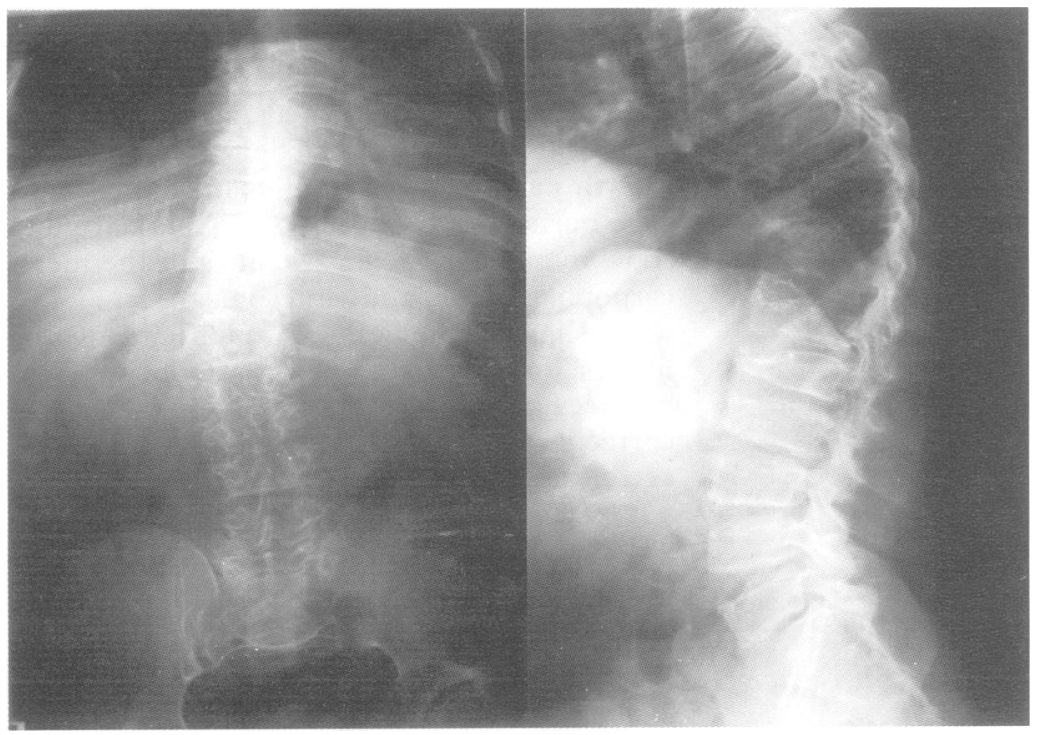

Figure 3 Subject VII. 7 (father of the proband) at the age of 35 years: anteroposterior and lateral views of the thoracolumbar spine showing gross platyspondyly with kyphoscoliosis more marked at the thoracolumbar junction. There is defective ossification of the anterior parts of the vertebral bodies. The vertebral body at L1 shows an anterior tongue-like deformity.

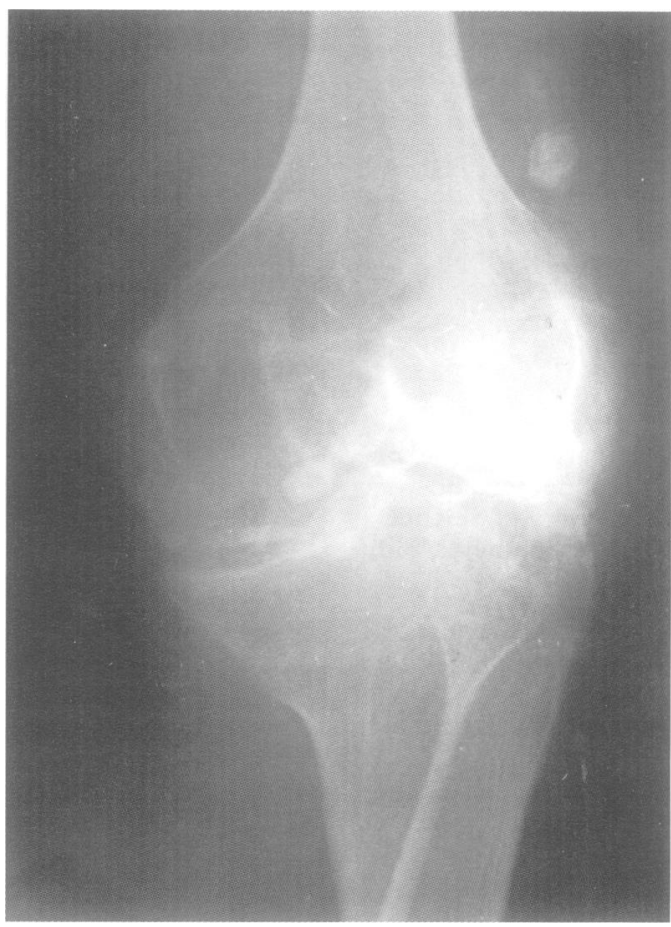

Figure 4 Subject VII.7 (father of the proband) at the age of 32 years: anteroposterior view of the knee showing severe secondary osteoarthritis with loss of the joint space. There are several loose bodies and subarticular cyst-like lesions with enlarged distal femoral epiphyses.

CASE 4

The father of the proband, VII.7, currently 37 years old, walked at the age of 8 months and was noticed to have bowing of his legs at the age of 3 years. At the age of 8 years he started to have joint swellings with minimal pain and limitation of movement. Contractures developed in the hips, knees, elbows, and wrists by the age of 20 , following a slowly progressive course. Progressive scoliosis was noticeable a few years later. Now, he has severe contractures of hips, knees, ankles, shoulders, elbows, and wrists with swelling and pain that is relieved by rest and non-steroidal antinflammatory drugs. $\mathrm{He}$ also has fusiform swelling with limitation of movement in most hand and foot joints. The face and head are normal.

The radiological findings in the spine were universal platyspondyly and kyphoscoliosis deformity (fig 3). Radiographs of the extremities showed flattened and enlarged epiphyses at the hips, knees, ankles, shoulders, elbows, and wrists with osteophytic lipping and loss of joint space (fig 4). There were signs of superimposed osteoarthritis with flexion deformities. The hand and foot radiographs showed enlarged epiphyses and metaphyses of the metacarpal, metatarsal, and phalangeal bones with loss of interphalangeal joint space and periarticular osteoporosis (fig 5). No soft tissue swellings or erosions could be seen.

CASE 5

The paternal aunt of the proband, VII.4, is currently 48 years old. She has a similar clinical and radiological picture to her brother (VII.7).

CASE 6

The paternal uncle of the proband, VII.6, died this year at the age of 52 years from ischaemic

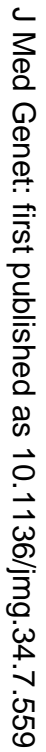




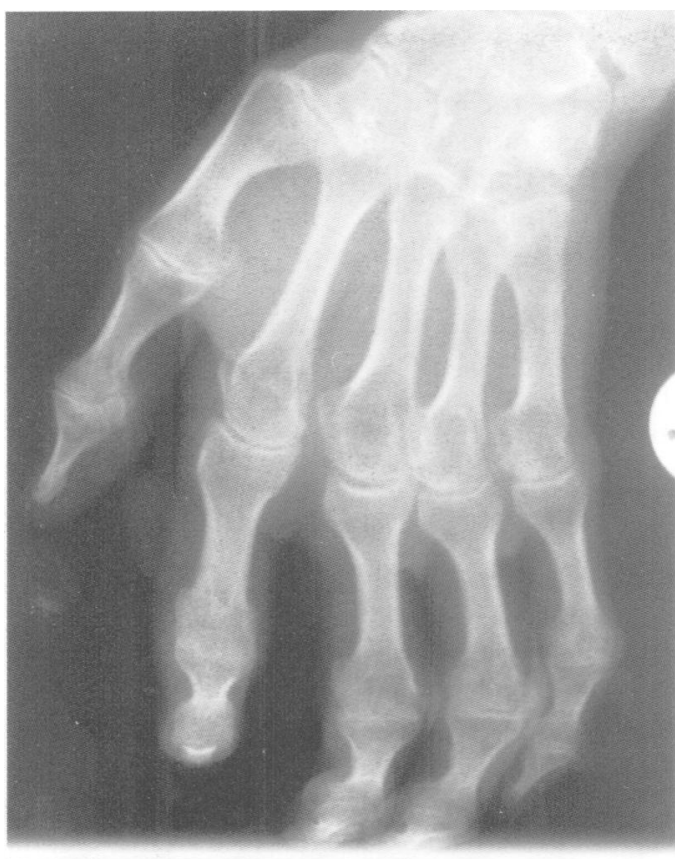

Figure 5 Subject VII.7 (father of the proband) at the age of 35 years: posteroanterior view of the hand showing fixed finger contractures with enlargement of the metacarpal and phalangeal epiphyses and metaphyses and periarticular osteoporosis.

heart disease. He had a similar clinical and radiological picture to his brother (VII.7).

\section{Discussion}

Including our family, there are over 45 reported subjects with progressive pseudorheumatoid dysplasia. ${ }^{1-16} 18-20$ It is our observation, as well as others', that the phenotypic expression of this disorder varies very little, in particular within the same family. ${ }^{16}$

\section{CLINICAL PICTURE}

The onset of the disease is between 3 and 11 years with the majority presenting before the age of $8 .^{1{ }^{25-12} 18}$ The presenting complaint is one or more of the following: walking difficulties, ${ }^{258}$ muscle weakness, ${ }^{218}$ easy fatiguability, ${ }^{2}$ pain and swelling in the joints, especially in the hands, ${ }^{1612}$ and deformities of the knee, genu valgum or varum..$^{6-8}{ }^{10}$ In our family, the presenting feature was bowing of the legs that started around the age of 3 years. Like the father, VII.7, the younger patients would have been misdiagnosed if not for the clear family history.

Overall, the adult height is moderately reduced although early in the disease it is usually within the normal range. ${ }^{12561018}$ This moderate reduction in height is explained by the progressive contractures in the hips and knees and the spine deformities. ${ }^{126}$ Where upper to lower body segment ratios were available, it was less than $1 .^{168}$ In our family, all the three younger patients are of normal height. However, Leguis et $a l^{15}$ reported two brothers and one sister, presumably with the disorder, who reached normal adult height.

Multiple joints are involved with pain, swelling, decreased mobility, and progressive deformity, including the hands, hips, elbows, knees, wrists, shoulders, ankles, feet, and intervertebral joints, in order of decreasing frequency. ${ }^{12}$ 5-12 One patient had involvement of the hand joints only. ${ }^{1}$ Scoliosis, kyphosis, or lordosis may develop. ${ }^{1} 101520$ There are no reports of the involvement of the temporomandibular joints. From observing our proband, the metacarpophalangeal and proximal interphalangeal joints were involved before the distal interphalangeal joints. This was also the experience of others who had the chance of witnessing the development of the disease in their patients. ${ }^{1}$

Whenever mentioned, all patients had a normal facial appearance and normal intelligence. ${ }^{126810}$ There was generalised weakness and mild progressive muscular atrophy in some patients. ${ }^{21820}$ Spranger et al ${ }^{19} 20$ noticed that none of their patients responded to any of the antirheumatic drugs whether steroidal or non-steroidal. One child reported a decrease in joint pain while on a non-steroidal antinflammatory drug, but without objective improvement of the swelling. ${ }^{14}$ In our family, patient VII.7 reported relief of joint pain with improved mobility, also without documented objective improvement. In the last two instances, the response is probably the result of the analgesic effect of these drugs. The joint swelling and contractures in this disorder clearly do not respond to antirheumatic drugs.

RADIOGRAPHIC PICTURE

The spine radiographs show universal platyspondyly, ${ }^{125-1215} 18$ although this is not the earliest radiographic finding. ${ }^{18}$ Our proband started showing platyspondyly by the age of 6 , while earlier radiographs were normal. Early on there are varying degrees of end plate irregularity. ${ }^{127}$ The vertebral bodies are ovoid without the posterior deformation of the plates which characterises spondyloepiphyseal dysplasia tarda. Scoliosis, kyphosis, especially thoracolumbar, and lordosis may be present. $^{1261215}$

Pelvic radiographs show enlarged capital femoral epiphyses in childhood; coxa vara and irregularities of the articular surface of the femur and acetabulum appear later. ${ }^{12}$ 5-12 $^{5}$ There is progressive loss of joint space, periarticular osteoporosis, and premature osteoarthritis. ${ }^{25-7} 15$

Radiographs of involved joints show widened epiphyses and metaphyses, loss of joint space with periarticular osteoporosis, and irregular articular surfaces. ${ }^{125-12} 1518$

The radiographic picture has been reviewed by Kozlowski et al. ${ }^{7}$

\section{SPECIAL INVESTIGATIONS}

Almost all reported patients, including ours, had some investigations done to exclude the diagnosis of a connective tissue disease. ${ }^{1} 25-8121820$ When done, erythrocyte sedimentation rate, $\mathrm{C}$ reactive protein, rheumatoid factors, antinuclear antibodies, and lupus erythematosus cells were always normal or negative. ${ }^{1268121820}$ One patient had a synovial biopsy which was reported as normal. ${ }^{2}$ Three patients had muscle biopsies; two were 
reported as normal and the third showed nonspecific, type II fibre atrophy. ${ }^{21}$ Electromyograms were normal and so were the muscle enzymes. ${ }^{20}$ One patient had a bone biopsy from the iliac crest which showed interesting results. ${ }^{2}$ There was abnormal nesting of chondrocytes, in both the resting and proliferative cartilage, embedded in a material that stained deeply with PAS-alcian blue and toluidin blue. The chondrocytes were polymorphous and many had pycnotic nuclei. There was defective columnisation of cells in growth zones but with normal osteoid formation and mineralisation. The ultrastructure of the chondrocytes showed that they had large golgi bodies, intracytoplasmic vesicles, and dilated endoplasmic reticulum cisterns. The collagen fibres were kinky with variable thickness and the ground substance within the nests was irregular with spiral bundles of non-striated fibres. The resected head of the femur of another patient, who was of normal adult height, was examined and found to show an end stage degenerative joint, an irregular trabecular pattern of bone, and formation of multiple cysts in the subchondral bone. $^{15}$

\section{DIFFERENTIAL DIAGNOSIS}

The disorder should be considered whenever the diagnosis of juvenile rheumatoid arthritis is entertained, especially when laboratory support of rheumatic disease is lacking. ${ }^{168}$ There is no associated fever and the radiographs never show the destructive lesions of rheumatoid arthritis. ${ }^{125-8} 18$ The progressive early multiple joint involvement differentiates it from other bony dysplasias. ${ }^{125-818}$ As with our experience, once the diagnosis is reached in one family member, diagnosing other affected members becomes easier. $^{6}$

\section{GENETICS}

The mode of inheritance in this disorder is clearly autosomal recessive. This is shown by the presence of affected sibs and normal parents. ${ }^{1256-7913-15}$ Consanguinity has been documented in our family, as well as several other families. ${ }^{1568-10}$ The extensive inbreeding in our family explains the presence of affected members in two successive generations and further supports the autosomal recessive pattern of inheritance. One report (in Italian) describes the mother of an affected child as showing "minimal features of the disease". ${ }^{16}$ Although the mother has reduced muscle mass, joint swelling, and moderate osteoporosis, the vertebrae are normal. Since in some autosomal recessive disorders, such as hypophosphatasia and Bardet-Biedl syndrome, milder manifestations may be found in the heterozygote, the finding of minimal features in this mother is still compatible with autosomal recessive inheritance. However, it also provokes the question of genetic heterogeneity of this disorder.

\section{NOMENCLATURE}

Although we promote the use of the international nomenclature, ${ }^{17}$ we suggest the addition of "spondyloepiphyseal" to the name of the disorder to become "progressive pseudorheumatoid spondyloepiphyseal dysplasia" (PPSED). This serves a dual purpose of comprehensively describing the pathology of the disease and rendering access to the available published reports easier.

\section{GEOGRAPHICAL DISTRIBUTION}

About two thirds of the reported patients are of Arabic origin. ${ }^{12689} \mathrm{~A}$ few patients have been reported from Greece and other countries of the Mediterranean basin. ${ }^{1216}$ Teebi and Al-Awadi ${ }^{8}$ recognised this high prevalence of the disease among Arabs, as they had access to unpublished data about families from Syria and Saudi Arabia. The two published large inbred families, ours and that of Al-Awadi et $a l,{ }^{6}$ are from Jordan.

\section{AETIOLOGY}

Since type II collagen is restricted to hyaline cartilage, nucleus pulposus, and vitreous humour of the eye, its defectiveness is reflected in the epiphyses of long bones, articular cartilage, the spine, and the eyes. Mutations in the COL2A1 gene have now been described in an entire family of dominant disorders (type II collagenopathies) which include achondrogenesis, hypochondrogenesis, Stickler arthro-ophthalmopathy, Kniest dysplasia, spondyloepiphyseal dysplasias, and spondyloarthropathy. ${ }^{21}{ }^{22}$ These facts encouraged Lewkonia and Bech-Hansen ${ }^{14}$ to study their reported family molecularly for abnormalities in the COL2A1 gene. Their techniques did not uncover any abnormalities in the gene, but did not completely exclude it as the disease causing gene. In the absence of eye manifestations and with the autosomal recessive inheritance, type II collagen defects seem unlikely but not impossible.

On the other hand, a recessive form of osteochondrodysplasia (early onset osteoarthritis with less severe spine involvement) has been linked to type XI collagen and a mutation in the COL11A2 gene has been found. ${ }^{23}$ Type IX collagen is also cartilage specific and has been implicated in some forms of multiple epiphyseal dysplasia. ${ }^{24}$ These two types of collagen are implicated in disorders that phenotypically overlap with progressive pseudorheumatoid dysplasia and are thus candidate genes for the disorder.

Wynne Davies R, Hall B, Ansell MB. Spondyloepiphysea dysplasia tarda with progressive arthropathy - a "new" disdysplasia tarda with progressive arthropath

2 Spranger J, Albert C, Schilling F, Bartsocas C, Stoss H. Progressive pseudorheumatoid arthritis of childhood (PPAC): a hereditary disorder simulating rheumatoid arthritis. Eur $\mathscr{f}$ Pediatr 1983;140:34-40.

3 Laplane R, Fontaine JL, Lagardere B, Sambury F. Nanisme syndesmodysplasique familial: une entite morbide nouvelle. Arch Fr Pediatr 1972;29:831-8.

Maroteaux P. Les maladies osseuses de l'enfant. Paris: Flammarion Médecin-Sciences, 1974:96-8.

5 Kaibara N, Takagishi K, Katsuki I, Eguchi M, Masumi S, Nishio A. Spondyloepiphyseal dysplasia tarda with progressive arthropathy. Skeletal Radiol 1983;10:13-16.

6 Al-Awadi SA, Farag TI, Naguib K, et al. Spondyloepiphyseal dysplasia tarda with progressive arthropathy. $\mathcal{F} \mathrm{Med}$ Genet 1984;21:193-6.

7 Kozlowski K, Kennedy J, Lewis IC. Radiographic features of progressive pseudorheumatoid arthritis. Australas Radiol 1986;30:244-50 
8 Teebi AS, Al-Awadi SA. Spondyloepiphyseal dysplasia tarda with progressive arthropathy: a rare disorder frequently diagnosed among Arabs. $\mathcal{F}$ Med Genet 1986;23:189-91.

9 Miladi M, Elleuch MH, Sellami S, Douik M. Dysplasie spondylo-epiphysiare tardive avec arthropathies spondylo-epiphysiare tardive avec arthropathies
progressives; a propos de trois observations. Int Orthop progressives; a

10 Robinson D, Tieder M, Halperin N, Copeliovitch I. Spondyloepiphyseal dysplasia associated with progressive arthropathy: an unusual disorder mimicking juvenile rheumatoid arthritis. Arch Orthop Trauma Surg 1989;108:397-9.
1 Archik SG, Kamat RD. Progressive pseudorheumatoid chondrodysplasia simulating juvenile rheumatoid arthritis. Indian f Pediatr 1990;57:785-8.

12 Sood S, Gupta AK, Berry M. Spondyloepiphyseal dysplasia tarda with progressive arthropathy. Indian 7 Pediatr 1991;28:671-3.

13 Diaz-Mares L, Gonzalez-del Angel A, Gutierrez-Castrellon P, Takenaga-Mesquida R, Carnevale A. Spondyloepiphyseal dysplasia tarda with progressive arthropathy: 19 siblings affected. Bol Med Hosp Infantil Mexico 1992;49: $678-82$.

14 Lewkonia RM, Bech-Hansen NT. Spondyloepiphyseal dysplasia tarda simulating juvenile arthritis: clinical and plasia tarda simulating juvenile arthritis: clinical and
molecular genetic observations. Clin Exp Rheumatol 1992; mo:411-14

15 Leguis E, Mulier M, Van Damme B, Fryns JP. Progressive pseudorheumatoid arthritis of childhood (PPAC) and normal adult height. Clin Genet 1993;44:152-5.
16 Rasore-Quartino A, Camera A, Camera G. Spondyloepiphyseal dysplasia tarda with progressive arthropathy: description of a patient whose mother showed minimal features of the disease. Pathologica 1993;85:225-31.

17 Beighton P, Geidion ZA, Gorlin R, et al. International classification of ZA, Gorlin R, al. Internation classification of osteochondrodysplasias. International Working Group on Constitutional Diseases of Bone. Am $\mathcal{F}$

8 Med Genet $1992,44.223-9$.

8 Perri G. The radiological features of a new bone dysplasia. Pediatr Radiol 1981;11:109-13.

19 Spranger J, Albert C, Schilling F. A progressive connective tissue disease with features of juvenile rheumatoid arthritis and osteochondrodysplasia. Eur $\mathcal{F}$ Pediatr 1980;133:187.

20 Spranger J, Albert C, Schilling F, Bartsocas C. Progressive pseudorheumatoid arthritis of childhood (PPAC): a hereditary disorder simulating rheumatoid arthritis. $\mathrm{Am} \mathcal{F}$ Med Genet 1983;14:399-401.

21 Rimoin DL, Cohn DH, Eyre D. Clinical-molecular correlations in the skeletal dysplasias. Pediatr Radiol 1994;24:425-6.

22 Spranger J, Winterpacht A, Zabel B. The type II collagenopathies: a spectrum of chondrodysplasias. Eur $\mathcal{F}$ Pediatr 1994;153:56-65.

23 Vikkula M, Mariman ECM, Lui VCH, et al. Autosomal dominant and recessive osteochondrodysplasias associated dominant and recessive osteochondrodysplasias

24 Briggs MD, Choi HC, Warman ML, et al. Genetic mapping of a locus for multiple epiphyseal dysplasia (EDM2) to a region of chromosome 1 containing a type IX collagen gene. Am F Hum Genet 1994;55:678-84. 